\title{
Status of prehospital delay and intravenous thrombolysis in the management of acute ischemic stroke in Nepal
}

\author{
Gaurav Nepal ${ }^{1 *} \mathbb{D}$, Jayant Kumar Yadav¹, Babin Basnet ${ }^{1}$, Tirtha Man Shrestha², Ghanshyam Kharel ${ }^{3}$ and Rajeev Ojha ${ }^{3}$
}

\begin{abstract}
Background: Intravenous thrombolysis has been recently introduced in Nepal for the management of acute ischemic stroke. Pre-hospital delay is one of the main reasons that hinder thrombolytic therapy. The objective of this study was to evaluate the status of prehospital delay and thrombolysis in Nepal.

Methods: Data were prospectively collected from patients of both genders, age $>18$ years who arrived at the emergency department (ED) with symptoms and neuroimaging findings consistent with an ischemic stroke. Patient data were obtained from ED form and standard questionnaires were used to assess factors resulting in prehospital delay. Modified Rankin scale and National Institute of Health stroke scale were used to assess the degree of disability and severity of stroke respectively.

Results: A total of 228 patients were enrolled in the study between August 2017 and August 2018. Only 46 (20.17\%) patients arrived within the time frame for thrombolysis. Onset at daytime (OR: 4.07; 95\% Cl: 1.65-10.1; $p=$ 0.001 ), stroke symptoms facial deviation (OR: $5.03 ; 95 \% \mathrm{Cl}: 2.47$ to $10.26 ; p=0.000$ ) and speech disturbances (OR: 2.34; $95 \%$ Cl: 1.06 to $5.1 ; p=0.021$ ), identification of stroke (OR: $22.36 ; 95 \% \mathrm{Cl}: 9.42-53.04 ; p=0.000$ ), rushing to ED after onset of symptoms (OR: 2.93; 95\% Cl: $1.5-5.7 ; p=0.001$ ), awareness of treatment of stroke (OR: 10.21; $95 \% \mathrm{Cl}$ : 4.8-21.6; $p=0.000$ ), direct presentation (OR: 4.2; 95\% Cl: 2.09-8.66; $p=0.000$ ), the distance less than $20 \mathrm{~km}$ (OR: 7.9; 95\% Cl: 3.8-16.5; $p=0.000)$, and education above high school (OR:4.85; 95\% Cl: $2.2-10.5 ; p=0.000$ ) were associated with early arrival. Heavy traffic, income below 1000 USD per annum and diabetes mellitus were associated with delayed arrival to ED. Out of 46 early arrival patients, only 30 patients (13.15\%) received tissue plasminogen activator during the study period, while others were deprived because of their inability to afford the treatment cost.

Conclusion: Community-based intervention to spread awareness, establishing comprehensive stroke centers, training specialists, improving emergency services, establishment of telestroke facilities and encouraging the use of low-cost tenecteplase as an alternative to alteplase can help improve care for stroke patients in Nepal.
\end{abstract}

Keywords: Stroke, Ischemic stroke, Pre-hospital delay, rtPA, Thrombolysis, Nepal

\section{Background}

According to the Global Burden of Disease Study, stroke is the second leading cause of death globally and the third leading cause of premature death and disability as measured in Disability Adjusted Life Years (DALY) [1]. Stroke also accounts for $4.1 \%$ of total global DALY producing immense health and economic burden globally

\footnotetext{
* Correspondence: gauravnepal@iom.edu.np

${ }^{1}$ Medical Student, Tribhuvan University Institute of Medicine, Maharajgunj,

Kathmandu, Nepal

Full list of author information is available at the end of the article
}

$[1,2]$. In 2013, stroke accounted for 6.5millions deaths worldwide of which $51 \%$ had suffered ischemic stroke. Similarly, 113 million DALYs were due to the stroke of which ischemic stroke comprised $58 \%$. In the same year, total new stroke cases recorded was 10.3 million of which $67 \%$ were ischemic type [2]. The majority of the burden of stroke continues to reside in developing countries comprising $75.2 \%$ of deaths from stroke and $81.0 \%$ of stroke-related DALYs [2]. According to data of the central referral hospital of Nepal, ischemic stroke

(c) The Author(s). 2019 Open Access This article is distributed under the terms of the Creative Commons Attribution 4.0 International License (http://creativecommons.org/licenses/by/4.0/), which permits unrestricted use, distribution, and 
accounted for $36.5 \%$ of all admitted cases in neurology ward and $73.8 \%$ of all admitted cases of stroke [3].

Until now, intravenous thrombolysis (IVT) with tissue plasminogen activator (t-PA) within $4.5 \mathrm{~h}$ and endovascular thrombectomy within $6 \mathrm{~h}$ are the only approved treatments for acute ischemic stroke $[4,5]$. The use of IVT for the management of ischemic stroke was introduced in Nepal in 2012 [6]. Endovascular thrombectomy is one of the recent advances in the treatment of ischemic stroke but has its own limitations. It is reserved for ischemic stroke of proximal large arteries in the anterior circulation but requires extensive setup and expertise which is not currently feasible in a limited resource setting of Nepal. Thus, IVT appears to be a better option for ischemic stroke patients in Nepal.

IVT has a very narrow therapeutic window and early arrival to the hospital for IVT with t-PA is of paramount importance for acute ischemic stroke management. However, only a small proportion of patients with ischemic stroke receive reperfusion therapy with IVT for which delayed presentation to hospitals is one of the most important limiting factors. Further, early thrombolysis is associated with good clinical outcomes compared to late thrombolysis even within therapeutic time window. Hence the benefit is strongly time-dependent $[7,8]$. To the best of our knowledge, there has been no study of prehospital delays in patients with acute ischemic stroke in Nepal. We, therefore, sought to evaluate the factors associated with delayed presentation to the hospital among patients who suffered an acute stroke in Nepal and the status of thrombolysis in Nepal.

\section{Methods}

This study was approved by the Institutional Review Board of Tribhuvan University, Institute of Medicine. The approval number for our study is $31(6-11-E)^{2} / 074 / 075$. Informed written consent was obtained from the patients themselves, where possible, and their accompanying family members. The site of patient enrollment was Tribhuvan University Teaching Hospital (TUTH) located in capital city Kathmandu. With 700-bed and 32 departments, it is the largest hospital in the country and tertiary referral center for all kinds of disease and conditions including stroke.

\section{Inclusion criteria}

Between August 2017 and August 2018, data were prospectively collected from patients of both sexes, age $>18$ years old, who arrived at the emergency department (ED) of TUTH with signs and symptoms corresponding to ischemic stroke and confirmed by neuroimaging.

\section{Exclusion criteria}

We excluded the patients who suffered from an ischemic stroke when in our hospital, patients with contraindication to thrombolysis, those having a hemorrhagic stroke and presenting 7 days after stroke symptoms, and patients with unknown duration of symptom onset. We excluded all the patients coming to our ED from places outside Kathmandu to prevent selection bias.

\section{Variables}

Time of stroke onset was defined as the time the patient or an observer first noted a neurological deficit. If the symptoms were present on waking, it was assumed that stroke had occurred during the night and the time of onset was taken when the patient was last seen without symptoms. The exact time of arrival at hospital was extracted from emergency room form. A standard structured questionnaire was filled by interviewing the patient (if possible) and family members/relatives after taking informed written consent. The questionnaire documented the patient's age, sex, educational level, the day of onset, financial status, symptoms, ability to identify stroke, past history, distance from the site where the event happened, response to symptoms, referral, patient's awareness of stroke treatment, and the mode of transportation. The modified Rankin Scale (mRS) was used for assessing the degree of disability [9]. The National Institute of Health Stroke Scale (NIHSS) was used for assessing stroke severity: mild (1-5), moderately severe (6-14), severe (15-24) and very severe (> 25) [10].

A threshold of $3 \mathrm{~h}$ was used to classify patients into two groups, i.e., arrival to the ED within $3 \mathrm{~h}$ after the onset of symptoms (non-delayed/early) or arrival beyond this time (delayed/late) [11]. The day of onset was divided into weekdays and holidays (Saturday, public holidays) and the time of onset was divided into daytime (from 7 am to $7 \mathrm{pm}$ ) and night-time (7 pm to $7 \mathrm{am}$ ) as they impact the arrival time. The site where the acute event happened was divided in the home and outside home and witness of symptoms onset was categorized into patient and others. Transportation variables included travel to the hospital by ambulance or by other methods (motorcycle, car, taxi).

Symptoms at onset included: Facial deviation or weakness, visual disturbance, limb weakness, speech disturbance, sensory disturbance, headache, and unconsciousness. Hypertension, diabetes, cardiovascular diseases, smoking, alcohol consumption and history of stroke were measured as risk factors for ischemic stroke.

\section{Statistical analysis}

Arrival time to ED after stroke was the dependent variable dichotomized as either early $(\leq 3 \mathrm{~h})$ or late $(>3 \mathrm{~h})$. Various other variables, as mentioned above, were independent variables. Univariate analyses (independent sample t-test for continuous variables, and $\chi^{2}$ test for categorical variables, as appropriate) were performed to 
assess the association of each of the independent variables and dependent variable. Explanatory variables, which were identified by univariate analysis at $P<0.2$, were selected and entered into a binary logistic regression model to identify predictors of an early arrival. All the statistical analyses were performed using SPSS 21 (IBM Corp. Released 2012. IBM SPSS Statistics for Windows, Version 21.0. Armonk, NY: IBM Corp.). For all statistical analysis, significance was accepted at $P<0.05$.

\section{Results}

\section{Patient selection}

During the study period, 412 patients arrived in the emergency department (ED) with stroke. Of the 412 stroke patients, 90 patients were excluded because plain CT head showed intracerebral hemorrhages. Among 322 ischemic stroke patients, 32 patients were excluded because they were coming from places outside Kathmandu city and 40 patients were excluded as they presented 7 days after the onset of symptoms. Likewise, twenty-two ischemic stroke patients were found to have contraindication to thrombolysis and were thus excluded. Finally, 228 ischemic stroke cases were included in our study as shown in Fig. 1.

\section{Patient characteristics}

There were a total of 228 ischemic stroke patients included in our study, 121(53.1\%) of them were male and
$154(67.5 \%)$ were above the age of 60 . On the basis of NIHSS, 62 (27.2\%) patients had a mild stroke, 140(61.2\%) had a moderately severe stroke, 19(8.3\%) had a severe stroke, and $7(3.1 \%)$ had a very severe stroke. On the basis of mRS, 28 (12.3\%) patients had no significant disability, 53(23.2\%) had a slight disability, 30(13.2\%) had a moderate disability, 59(25.9\%) had a moderately severe disability, and $58(25.4 \%)$ had a severe disability. In terms of symptoms at onset, 94 patients (41.2\%) developed facial deviation or weakness, 23 patients $(10.1 \%)$ developed visual disturbances, 154 patients $(67.5 \%)$ developed limb weakness, 153 patients (67.1\%) developed speech disturbances, 11 patients (4.8\%) developed sensory disturbances, 39 patients (17.1\%) had headache, and 34 patients $(14.9 \%)$ became unconscious. According to patient's history, hypertension was found in 128 patients (56.1\%), diabetes in 40 patients (17.5\%), smoking in 66 patients (28.9\%), significant alcohol consumption in 62 patients $(27.2 \%)$, coronary heart disease in 21 patients (9.2\%), and previous stroke in 27(11.8\%). All other patient characteristics are tabulated in Table 1.

\section{Univariate analysis of factors associated with prehospital delay}

The early group had 46 patients $(20.2 \%)$ and the late group had 182 patients $(79.8 \%)$. In the univariate analysis (Table 2), onset at daytime (OR: 4.07; 95\% CI: 1.65




Table 1 Baseline characteristics of the study population

\begin{tabular}{|c|c|c|}
\hline Characteristics & & N (\%) \\
\hline \multirow[t]{2}{*}{ Age } & $<60$ & $74(32.5)$ \\
\hline & $>60$ & $154(67.5)$ \\
\hline \multirow[t]{2}{*}{ Sex } & Male & $121(53.1)$ \\
\hline & Female & $107(46.9)$ \\
\hline \multirow[t]{2}{*}{ Arrival } & Early & $46(20.17)$ \\
\hline & Late & $\begin{array}{l}182 \\
(79.83)\end{array}$ \\
\hline \multirow[t]{2}{*}{ Time of onset } & $7 \mathrm{am}-7 \mathrm{pm}$ & $153(67.1)$ \\
\hline & $7 \mathrm{pm}-7 \mathrm{am}$ & 75 (32.9) \\
\hline \multirow[t]{2}{*}{ Day of onset } & Weekday & $183(80.3)$ \\
\hline & Holiday & $45(19.7)$ \\
\hline \multirow[t]{2}{*}{ Location } & Home & $192(84.2)$ \\
\hline & Outside home & $36(15.8)$ \\
\hline \multirow[t]{2}{*}{ Identification of stroke } & Yes & $36(15.8)$ \\
\hline & No & $192(84.2)$ \\
\hline \multirow[t]{2}{*}{ Facial palsy } & Yes & $94(41.2)$ \\
\hline & No & $134(58.5)$ \\
\hline \multirow[t]{2}{*}{ Visual disturbances } & Yes & $23(10.1)$ \\
\hline & No & $205(89.9)$ \\
\hline \multirow[t]{2}{*}{ Limb weakness } & Yes & $154(67.5)$ \\
\hline & No & $74(32.5)$ \\
\hline \multirow[t]{2}{*}{ Speech disturbances } & Yes & $153(67.1)$ \\
\hline & No & $75(32.9)$ \\
\hline \multirow[t]{2}{*}{ Sensory } & Yes & $11(4.8)$ \\
\hline & No & $217(95.2)$ \\
\hline \multirow[t]{2}{*}{ Headache } & Yes & $39(17.1)$ \\
\hline & No & $189(82.9)$ \\
\hline \multirow[t]{2}{*}{ Unconsciousness } & Yes & $34(14.9)$ \\
\hline & No & $194(57.9)$ \\
\hline \multirow[t]{2}{*}{ Response of symptoms } & Rush to emergency & $96(42.1)$ \\
\hline & $\begin{array}{l}\text { Wait for symptoms to } \\
\text { subside }\end{array}$ & $132(57.9)$ \\
\hline \multirow{2}{*}{$\begin{array}{l}\text { Awareness of stroke } \\
\text { treatment }\end{array}$} & Yes & $44(19.3)$ \\
\hline & No & $184(80.7)$ \\
\hline \multirow[t]{2}{*}{ Presentation to ER } & Direct & $101(44.3)$ \\
\hline & Referral & $127(55.7)$ \\
\hline \multirow[t]{2}{*}{ Transportation } & Ambulance & $70(30.7)$ \\
\hline & Others & $158(69.3)$ \\
\hline \multirow[t]{2}{*}{ Traffic jam } & Present & $107(46.9)$ \\
\hline & Not present & $121(53.1)$ \\
\hline \multirow[t]{2}{*}{ Distance from hospital } & $<20 \mathrm{KM}$ & $82(36)$ \\
\hline & $>20 \mathrm{KM}$ & $146(64)$ \\
\hline \multirow[t]{2}{*}{ Education } & Above high school & $34(14.9)$ \\
\hline & Below high school & $194(85.1)$ \\
\hline Income & $>1$ lacks per annum & $106(46.5)$ \\
\hline
\end{tabular}

Table 1 Baseline characteristics of the study population (Continued)

\begin{tabular}{lll}
\hline Characteristics & & N (\%) \\
\hline \multirow{3}{*}{ Hypertension } & $<1$ lacks per annum & $122(53.5)$ \\
Diabetes mellitus & Yes & $128(56.1)$ \\
& Yes & $100(43.9)$ \\
Smoking & No & $40(17.5)$ \\
& Yes & $188(82.5)$ \\
Alcohol consumption & No & $66(28.9)$ \\
& Yes & $162(71.1)$ \\
Coronary arterial disease & No & $62(27.2)$ \\
& Yes & $166(72.8)$ \\
History of stroke & No & $21(9.2)$ \\
& Present & $207(90.8)$ \\
Treatment & Not present & $27(11.8)$ \\
& R-tPA & $201(88.2)$ \\
& Aspirin & $30(13.15)$ \\
& & 198 \\
\hline
\end{tabular}

to $10.1 ; p=0.001)$, stroke symptoms facial deviation (OR: 5.03; 95\% CI: 2.47 to $10.26 ; p=0.000$ ) and speech disturbances (OR: 2.34; 95\% CI: 1.06 to $5.1 ; p=0.021$ ), identification of stroke (OR: 22.36; 95\% CI: 9.42 to 53.04; $p=0.000$ ), rushing to ED after onset of symptoms (OR: 2.93 ; $95 \%$ CI: 1.5 to $5.7 ; p=0.001$ ), awareness of treatment of stroke (OR: 10.21; 95\% CI: 4.8 to $21.6 ; p=$ 0.000), direct presentation (OR: 4.2; 95\% CI: 2.09 to 8.66 ; $p=0.000$ ), the distance less than $20 \mathrm{~km}$ (OR: 7.9; 95\% CI: 3.8 to $16.5 ; p=0.000)$, and education above high school (OR:4.85; 95\% CI: 2.2 to $10.5 ; p=0.000$ ) were associated with early arrival. Presence of heavy traffic, income below 1000 USD per annum and diabetes mellitus were associated with delayed arrival to ED. Age, sex, date, location, limb weakness, visual impairment, sensory disturbances, unconsciousness, headache, transportation, hypertension, smoking, alcohol consumption, coronary heart disease, and past history of stroke did not reach statistical significance. The mean NIHSS and mRS did not differ between the two groups.

\section{Logistic regression analysis}

To identify the independent predictors of a reduced prehospital delay (early arrival), we used the logistic regression model. Logistic regression showed that location inside home, rushing to the emergency after symptoms onset, absence of traffic jam, and income above 1000 USD were all independent predictors of a reduced prehospital delay, whereas failure to identify stroke, no awareness of stroke treatment, and distance $>20 \mathrm{~km}$ were associated with delayed arrival to ED (Table 3). 
Table 2 Association between study variables and early arrival at emergency department

\begin{tabular}{|c|c|c|c|c|c|c|}
\hline Study variables & & Early n (\%) & Late n (\%) & Odds ratio (OR) & 95\% C.I. & $P$ value \\
\hline \multirow[t]{2}{*}{ Age } & $<60$ & $18(39.1)$ & $56(30.8)$ & 1.44 & $0.74-2.8$ & 0.18 \\
\hline & $>60$ & $28(60.9)$ & $126(69.2)$ & 1 & Reference & \\
\hline \multirow[t]{2}{*}{ Sex } & Male & $25(54.3)$ & $96(52.7)$ & 1.066 & $0.56-2.04$ & 0.49 \\
\hline & Female & $21(45.7)$ & $86(47.3)$ & 1 & Reference & \\
\hline \multirow[t]{2}{*}{ Time of onset } & $7 \mathrm{am}-7 \mathrm{pm}$ & $40(87)$ & $113(62.1)$ & 4.07 & $1.65-10.1$ & 0.001 \\
\hline & 7 pm-7 am & $6(13)$ & 69 (37.9) & 1 & Reference & \\
\hline \multirow[t]{2}{*}{ Day of onset } & Weekday & $41(89.1)$ & $142(78)$ & 2.31 & $0.85-6.23$ & 0.064 \\
\hline & Holiday & $5(10.9)$ & $40(22)$ & 1 & Reference & \\
\hline \multirow[t]{2}{*}{ Location } & Home & $42(91.3)$ & $150(82.4)$ & 2.24 & $0.75-6.6$ & 0.101 \\
\hline & Outside home & $4(8.7)$ & $32(17.6)$ & 1 & Reference & \\
\hline \multirow[t]{2}{*}{ Identification of stroke } & Yes & $26(56.5)$ & $10(5.5)$ & 22.36 & $9.42-53.04$ & 0.000 \\
\hline & No & $20(43.5)$ & $172(94.5)$ & 1 & Reference & \\
\hline \multirow[t]{2}{*}{ Facial palsy } & Yes & $33(71.7)$ & $61(33.5)$ & 5.03 & $2.47-10.26$ & 0.000 \\
\hline & No & $13(28.3)$ & $121(66.5)$ & 1 & Reference & \\
\hline \multirow[t]{2}{*}{ Visual disturbances } & Yes & $3(6.55)$ & $20(11)$ & 0.563 & $0.16-1.99$ & 0.276 \\
\hline & No & $43(93.45)$ & $162(89)$ & 1 & Reference & \\
\hline \multirow[t]{2}{*}{ Limb weakness } & Yes & $32(69.6)$ & $122(67)$ & 1.124 & $0.56-2.26$ & 0.445 \\
\hline & No & $14(30.4)$ & $60(33)$ & 1 & Reference & \\
\hline \multirow[t]{2}{*}{ Speech disturbances } & Yes & $37(80.4)$ & $116(63.7)$ & 2.34 & $1.06-5.1$ & 0.021 \\
\hline & No & $9(19.6)$ & $66(36.3)$ & 1 & Reference & \\
\hline \multirow[t]{2}{*}{ Sensory } & Yes & $1(2.2)$ & $10(5.5)$ & 0.382 & $0.05-3.06$ & 0.31 \\
\hline & No & $45(97.8)$ & $172(94.5)$ & 1 & Reference & \\
\hline \multirow[t]{2}{*}{ Headache } & Yes & $10(21.7)$ & $29(15.9)$ & 1.46 & $0.65-3.27$ & 0.233 \\
\hline & No & $36(78.3)$ & $153(84.1)$ & 1 & Reference & \\
\hline \multirow[t]{2}{*}{ Unconsciousness } & Yes & $3(6.5)$ & $31(17)$ & 0.34 & $0.1-1.1$ & 0.053 \\
\hline & No & $43(93.5)$ & $151(83)$ & 1 & Reference & \\
\hline \multirow[t]{2}{*}{ Response of symptoms } & Rush to emergency & $29(63)$ & $67(36.8)$ & 2.93 & $1.5-5.7$ & 0.001 \\
\hline & Wait for symptoms to subside & $17(37)$ & $115(63.2)$ & 1 & Reference & \\
\hline \multirow[t]{2}{*}{ Awareness of stroke treatment } & Yes & $25(54.3)$ & $19(10.4)$ & 10.21 & $4.8-21.6$ & 0.000 \\
\hline & No & $21(45.7)$ & $163(89.6)$ & 1 & Reference & \\
\hline \multirow[t]{2}{*}{ Presentation to ER } & Direct & $33(71.7)$ & $68(37.4)$ & 4.2 & $2.09-8.66$ & 0.000 \\
\hline & Referral & $13(28.3)$ & $114(62.6)$ & 1 & Reference & \\
\hline \multirow[t]{2}{*}{ Transportation } & Ambulance & $19(41.3)$ & $51(28)$ & 1.8 & $0.92-3.5$ & 0.06 \\
\hline & Others & $27(28.7)$ & $131(72)$ & 1 & Reference & \\
\hline \multirow[t]{2}{*}{ Traffic jam } & Present & $10(21.7)$ & $97(53.3)$ & 0.243 & $0.11-0.52$ & 0.000 \\
\hline & Not present & $36(78.3)$ & $85(46.7)$ & 1 & Reference & \\
\hline \multirow[t]{2}{*}{ Distance from hospital } & $<20 \mathrm{KM}$ & $34(73.9)$ & $48(26.4)$ & 7.9 & $3.8-16.5$ & 0.000 \\
\hline & $>20 \mathrm{KM}$ & $12(26.1)$ & $134(73.6)$ & 1 & Reference & \\
\hline \multirow[t]{2}{*}{ Education } & Above high school & $16(34.8)$ & $18(9.9)$ & 4.85 & $2.2-10.5$ & 0.000 \\
\hline & Below high school & $30(65.2)$ & $164(90.1)$ & 1 & Reference & \\
\hline \multirow[t]{2}{*}{ Income } & $<1$ lacks per annum & $32(69.6)$ & $90(49.5)$ & 0.42 & $0.21-0.85$ & 0.011 \\
\hline & $>1$ lacks per annum & $14(30.4)$ & $92(50.5)$ & 1 & Reference & \\
\hline \multirow[t]{2}{*}{ Hypertension } & Yes & $29(63)$ & $99(54.4)$ & 1.43 & $0.73-2.7$ & 0.187 \\
\hline & No & $17(37)$ & $83(45.6)$ & 1 & Reference & \\
\hline
\end{tabular}


Table 2 Association between study variables and early arrival at emergency department (Continued)

\begin{tabular}{|c|c|c|c|c|c|c|}
\hline Study variables & & Early n (\%) & Late n (\%) & Odds ratio (OR) & 95\% C.I. & $P$ value \\
\hline \multirow[t]{2}{*}{ Diabetes mellitus } & Yes & $3(6.5)$ & $37(20.3)$ & 0.273 & $0.08-0.9$ & 0.018 \\
\hline & No & $43(93.5)$ & $145(79.7)$ & 1 & Reference & \\
\hline \multirow[t]{2}{*}{ Smoking } & Yes & $11(23.9)$ & $55(30.2)$ & 0.72 & $0.35-1.5$ & 0.257 \\
\hline & No & $35(76.1)$ & $127(69.8)$ & 1 & Reference & \\
\hline \multirow[t]{2}{*}{ Alcohol consumption } & Yes & $15(32.6)$ & $47(25.8)$ & 1.4 & $0.7-2.8$ & 0.228 \\
\hline & No & $31(63.4)$ & $135(74.2)$ & 1 & Reference & \\
\hline \multirow[t]{2}{*}{ Coronary arterial disease } & Yes & $5(10.9)$ & $16(8.8)$ & 1.26 & $0.43-3.6$ & 0.422 \\
\hline & No & $41(89.1)$ & $166(91.2)$ & 1 & Reference & \\
\hline \multirow[t]{2}{*}{ History of stroke } & Present & $9(19.6)$ & $18(9.9)$ & 2.21 & $0.92-5.3$ & 0.06 \\
\hline & Not present & $37(80.4)$ & $164(90.1)$ & 1 & Reference & \\
\hline \multirow[t]{2}{*}{ Baseline score at admission (mean $\pm \mathrm{SD}$ ) } & $\mathrm{mRS}$ & $3.02 \pm 1.42$ & $3.36 \pm 1.37$ & NA & NA & 0.143 \\
\hline & NIHSS & $7.58 \pm 3.87$ & $8.06 \pm 5.26$ & NA & NA & 0.568 \\
\hline
\end{tabular}

\section{Thrombolysis}

Overall, only 46 patients arrived at the hospital early, out of which 30 patients (13.15\%) received tissue plasminogen activator during the study period. Sixteen patients even after an early arrival were deprived of thrombolysis. None of the patients in the late arrival group received thrombolysis.

\section{Discussion}

The results of our study suggest that there is considerable pre-hospital delay among patients with acute stroke in Nepal. Identification of stroke, awareness of stroke treatment, education above high school and rushing to the emergency after the onset of symptom all shortened the prehospital delay. Among all major symptoms of stroke, only facial deviation or weakness, and speech disturbances were associated with a shortened prehospital delay in our study. Symptoms like facial deformity or speech disturbances are uncommon and the patient or witness might take these symptoms as warning signs of some serious diseases leading to early arrival to the hospital. On the other hand, limb weakness, headache and sensory disturbances are not exclusive to stroke and they might take these symptoms as part of mild diseases or some psychiatric illnesses. Moreover, health seeking behavior among Nepalese people is poor [12, 13]. In a study related to cognitive and behavioral aspects of ischemic stroke, $59 \%$ of affected patients expected their symptoms to disappear spontaneously, and $25 \%$ of witnesses waited to see if the patient's symptoms resolved spontaneously [14]. Studies have found that less than half of patients recognize they are having a stroke [14] or TIA [15], and some incorrectly attribute the symptoms to stress or fatigue, vision problems, migraine or heart attack $[14,15]$.

In our study, a visit to a local medical center was also associated with a late arrival, consistent with previous studies conducted in India and Taiwan [16, 17]. This is surprising since we expect medical professionals to readily detect the symptoms of a stroke and quickly refer the patient to the nearest tertiary hospital with thrombolysis service. Ours is one of the few hospitals in the city where a thrombolysis service is available, and lack of this information even among medical professionals can be a barrier to early referral. In our study, transportation by ambulance was not associated with prehospital delay. Studies have shown that the use of ambulances can shorten prehospital delay [18-20]. In our study, transfer by ambulance was observed only in $30.2 \%$ cases whereas this exceeds $50 \%$ in developed countries [21-23].

Table 3 Final logistic regression model results

\begin{tabular}{llllll}
\hline Predictor variables & $\beta$ estimate & Standard error & $P$ value & Exp(B) & $95 \%$ C.I. for EXP(B) \\
\hline Location: Inside home & 2.179 & 0.464 & 0.000 & 8.836 & $(3.559,21.937)$ \\
Identification of stroke: No & -2.148 & 0.640 & 0.001 & 0.117 & $(0.033,0.409)$ \\
Response of symptoms: Rush to emergency & 1.336 & 0.591 & 0.024 & 3.805 & $(1.196,12.107)$ \\
Awareness of stroke treatment: No & -1.961 & 0.614 & 0.001 & 0.141 & $(0.042,0.469)$ \\
Traffic Jam: No & 1.230 & 0.437 & 0.005 & 3.421 & $(1.453,8.054)$ \\
Distance: > 20 KM & -1.266 & 0.432 & 0.003 & 0.282 & $(0.121,0.658)$ \\
Income above 1000 USD & 1.259 & 0.427 & 0.003 & 3.521 & $(1.524,8.136)$ \\
\hline
\end{tabular}


Emergency medical care system in Nepal is still in its infancy which is not readily available everywhere and is also considered expensive, and thus people prefer other modes of transportation for patient transfer. Heavy traffic, and the distance greater than $20 \mathrm{~km}$ was associated with delayed arrival to the emergency. Onset of a stroke at daytime was associated with an early arrival to the emergency. Our finding was in disagreement with other studies [21, 24]. This discrepancy can be explained by the fact that ambulance services and other modes of transportation are not always available and reliable at night in Nepal due to a limited number of ambulances, geographical condition and poor communication service of the country.

The onset of symptoms at home was not associated with prehospital delay in univariate analysis. However, it was independently associated with reduced prehospital delay in logistic regression model. While we do not know the exact reason, hesitancy, and concern for possible police inquiry may be seen as perceived barriers to rapid hospital transfer by the bystander. Diabetes mellitus was associated with delayed arrival to the emergency which is similar to observations made by Hong et al. and Song et al. [21, 23]. Symptoms of a stroke such as limb weakness, slurring speech, sensory disturbances, dizziness, and unconsciousness may be misinterpreted as autonomic disturbances following hypoglycemic episode. Such patients may involve in self-management and overlook or ignore new symptoms $[25,26]$.

Our study showed that a low income was associated with significant prehospital delay. Most of the medical care in Nepal, including emergency care, is paid out of pocket, often increasing the financial barrier to service utilization [27, 28]. Worse, even in the case of an emergency, the patient must pay first and then receive the service later. Health insurance coverage is minimal in Nepal, limited to a few cities and inaccessible to the poor. Nepal government launched a public health insurance plan in 2016/17, but it seems to be ineffective as it avails health services only up to $\$ 500$ per head per year per family [28]. The limited amount of health cover discourages people to register for this plan. Poor financial status has several implications. It delays help seeking, transportation and affects decision making to undertake thrombolysis or not. Despite any contraindications, sixteen patients were deprived of thrombolysis even after reaching on time. Nepal is a low-income country, and recent data shows an annual per capita GDP of only \$ 850. Alteplase is available as $50-\mathrm{mg}$ vial in Nepal and costs 650 USD per $50-\mathrm{mg}$ vial. Since the standard dose of alteplase for treatment of ischemic stroke is $0.9 \mathrm{mg} /$ $\mathrm{kg}$, a person weighing $55.5 \mathrm{~kg}$ or below requires one 50 $\mathrm{mg}$ vial and person weighing above $55.5 \mathrm{~kg}$ will require two 50-mg vial. Therefore, even after excluding all other laboratory, imaging, and therapeutic costs, the cost of thrombolysis alone using alteplase range from 650 USD to 1000 USD [29, 30]. This makes thrombolysis treatment exorbitant for poor patients. The increasing evidence for low-cost alternative tenecteplase offers hope for such patients [30-32]. In Nepal, tenecteplase is easily available as 30-mg vials which cost 450 USD. So the cost of thrombolysis using tenecteplase (Standard dose 0.25 $\mathrm{mg} / \mathrm{kg}$ i.e. one $30-\mathrm{mg}$ vial for $120 \mathrm{~kg}$ adult) will be around 450 USD, which is substantially affordable than using alteplase. Sometimes, if two ischemic stroke patients with the weight below $60 \mathrm{~kg}$ arrive at the same time, tenecteplase can even be shared between two patients to reduce the cost (225 USD). This has been practiced a few times at our center.

Many challenges exist for the patients, physicians, and healthcare systems, especially in low to middle income countries. With the rapidly changing face of healthcare in Nepal, some of these challenges can be tackled. Health promotion strategies to improve community awareness of early identification of symptoms of stroke, the importance of time window, rapid hospital transfer and encouraging the use of ambulance services may considerably reduce prehospital delay. Establishment of comprehensive stroke centers, developing central emergency medical services (EMS), and telestroke facility would go a long way in helping our cause. Telestroke can enable any trained physician located in tertiary hospital to conduct a rapid clinical assessment and can provide treatment recommendations for the local team of doctors [33]. In a meta-analysis conducted by Baratloo et al., telestroke significantly reduced onset-to-door and hospital-stay durations in stroke patients without increasing the risk of mortality or symptomatic intracranial hemorrhage [34]. However, at present, for establishing telestroke network, exorbitant set-up costs are required, which is prohibitive for the resource limited countries in which they are needed the most. But a recent study in India found that telestroke services based on smartphones are a cheaper alternative to video conferencing telestroke services and are more portable with fewer technical failures [35]. The government of Nepal can run a program to provide thrombolytic agents free of cost to poor and needy people. Justifiable use of tenecteplase can also help bring down the cost of thrombolysis.

The strength of this study is that we prospectively analyzed data for a relatively large sample from the largest tertiary hospital in Nepal. Our study is also one of the few reports on this issue in this part of the world and the first report of its kind from Nepal. However, the study has some limitations that need to be addressed. Firstly, this study was based on a single institute in the capital city. Thus, our result might not reflect the 
experience of patients with stroke in other cities and rural area. These limitations should be considered when interpreting the study results. Multicentered studies are required to assess the factors for the prehospital delay before we generalize these findings so that we can improve care for stroke patients.

\section{Conclusions}

Prehospital delay is a major concern among stroke patients. Timely arrival to the hospital offers an opportunity for reperfusion therapy and good outcomes. Only $20 \%$ patients arrived in time frame for thrombolysis and 13.15\% received thrombolysis. Many of the factors contributing to the delay in treatment after the onset of stroke can be overcome. We recommend community-based interventions to spread awareness about stroke and its related symptoms and the importance of timely hospital transfer in such patients. Concerned authorities should focus on the development of stroke centers, training specialists, and develop central emergency medical services. Use of low-cost tenecteplase as an alternative to alteplase should be encouraged to bring down the cost of reperfusion therapy. In resource limited settings, the establishment of telestroke facilities may be a viable option.

\section{Abbreviations}

CT: Computed tomography; DALY: Disability adjusted life years;

ED: Emergency department; EMS: Emergency medical services; GDP: Gross domestic product; IVT: Intravenous thrombolysis; MRI: Magnetic resonance imaging; mRS: Modified rankin scale; NIHSS: National institute of health stroke scale; t-PA: Tissue plasminogen activator; USD: United stated dollars

\section{Acknowledgments}

We would like to thank Dr. Bikram Prasad Gajurel, Dr. Ravi Ranjan Pradhan, Mr. Amar Jayswal, Mr. Madhav Rijal and Mr. Milan Regmi for their valuable help.

\section{Authors' contributions}

Study concept and design: GN, JKY, RO, GK, BB, and TMS. Data collection: GN, $\mathrm{BB}$ and GK. Analysis and interpretation of data: GN, JKY, TMS, and RO. Drafting of the manuscript: GN, JKY, RO and TMS. All authors read and approved the final manuscript.

\section{Funding}

We received no funds for conducting this study.

\section{Availability of data and materials}

The data sets used and analyzed in this study are available from the corresponding author on reasonable request.

\section{Ethics approval and consent to participate}

Our study was approved by the Institutional Review Board, Tribhuvan University Institute of Medicine. The approval number for our study is 31(6$11-E)^{2} / 074 / 075$. The research adhered to the tenets of the Declaration of Helsinki as amended in 2008. Informed written consent was obtained from the patients themselves, where possible, and their accompanying family members.

\section{Consent for publication}

Not applicable.

\section{Competing interests}

None of the authors has any conflict of interest to disclose. We confirm that we have read the Journal's position on issues involved in ethical publication and affirm that this report is consistent with those guidelines.

\section{Author details}

'Medical Student, Tribhuvan University Institute of Medicine, Maharajgunj, Kathmandu, Nepal. ${ }^{2}$ Department of General Practice and Emergency Medicine, Tribhuvan University Institute of Medicine, Maharajgunj, Kathmandu, Nepal. ${ }^{3}$ Department of Neurology, Tribhuvan University Institute of Medicine, Maharajgunj, Kathmandu, Nepal.

Received: 11 March 2019 Accepted: 25 June 2019

Published online: 09 July 2019

\section{References}

1. Lozano R, Naghavi M, Foreman K, et al. Global and regional mortality from 235 causes of death for 20 age groups in 1990 and 2010: a systematic analysis for the global burden of disease study 2010. Lancet. 2012;380:2095-128.

2. Feigin $V L$, Krishnamurthi RV, Parmar P, Norrving B, Mensah GA, Bennett DA, Barker-Collo S, Moran AE, Sacco RL, Truelsen T, Davis S. Update on the global burden of ischemic and hemorrhagic stroke in 1990-2013: the GBD 2013 study. Neuroepidemiology. 2015;45(3):161-76.

3. Gajurel BP, Parajuli P, Nepali R, Oli KK. Spectrum of neurological disorders admitted in Tribhuvan University teaching hospital Maharajgunj. J Insur Med. 2013;34(3):50-3.

4. Berkhemer OA, Fransen PS, Beumer D, Van Den Berg LA, Lingsma HF, Yoo AJ, Schonewille WJ, Vos JA, Nederkoorn PJ, Wermer MJ, van Walderveen MA. A randomized trial of intraarterial treatment for acute ischemic stroke. N Engl J Med. 2015;372(1):11-20.

5. Hacke W, Kaste M, Bluhmki E, Brozman M, Dávalos A, Guidetti D, et al. ECASS investigators. Thrombolysis with alteplase 3 to 4.5 hours after acute ischemic stroke. N Engl J Med. 2008;359:1317-29.

6. Thapa L, Shrestha S, Shrestha P, Bhattarai S, Gongal DN, Devkota UP. Feasibility and efficacy of thrombolysis in acute ischemic stroke: a study from National Institute of neurological and allied sciences, Kathmandu, Nepal. J neurosci Rural Pract. 2016;7(1):55.

7. Khatri P, Yeatts SD, Mazighi M, Broderick JP, Liebeskind DS, Demchuk AM, et al. Time to angiographic reperfusion and clinical outcome after acute ischemic stroke: an analysis of data from the interventional Management of Stroke (IMS III) phase 3 trial. Lancet Neurol. 2014;13:567-74.

8. Emberson J, Lees KR, Lyden P, Blackwell L, Albers G, Bluhmki E, et al. Effect of treatment delay, age, and stroke severity on the effects of intravenous thrombolysis with alteplase for acute ischemic stroke: a meta-analysis of individual patient data from randomised trials. Lancet. 2014;384:1929-35.

9. Sulter G, Steen C, De Keyser J. Use of the Barthel index and modified Rankin scale in acute stroke trials. Stroke. 1999;30(8):1538-41.

10. Brott T, Adams HP Jr, Olinger CP, Marler JR, Barsan WG, Biller J, Spilker J, Holleran R, Eberle R, Hertzberg V. Measurements of acute cerebral infarction: a clinical examination scale. Stroke. 1989;20(7):864-70.

11. Siddiqui M, Siddiqui SR, Zafar A, Khan FS. Factors delaying hospital arrival of patients with acute stroke. JPMA J Pak Med Assoc. 2008;58(4):178-82.

12. Adhikari D, Rijal DP. Factors affecting health seeking behavior of senior citizens of Dharan. Journal of Nobel Medical College. 2014;3(1):50-7.

13. Baral R, Sapkota P. Health seeking behaviour among elderly people of Bharatpur municipality of Chitwan District, Nepal. JCMS Nepal. 2018;14(3): 150-3.

14. Shah M, Makinde KA, Thomas P. Cognitive and behavioral aspects affecting early referral of acute stroke patients to hospital. J Stroke Cerebrovasc Dis. 2007;16(2):71-6.

15. Giles MF, Flossman E, Rothwell PM. Patient behavior immediately after transient ischemic attack according to clinical characteristics, perception of the event, and predicted risk of stroke. Stroke. 2006;37(5):1254-60.

16. Ashraf W, Maneesh M, Praveenkumar R, Saifudheen K, Girija AS. Factors delaying hospital arrival of patients with acute stroke. Ann Indian Acad Neurol. 2015:18(2):162

17. Chang KC, Tseng MC, Tan TY. Prehospital delay after acute stroke in Kaohsiung, Taiwan. Stroke. 2004;35(3):700-4.

18. Nedeltchev K, Arnold M, Brekenfeld C, Isenegger J, Remonda L, Schroth G, Mattle HP. Pre-and in-hospital delays from stroke onset to intra-arterial thrombolysis. Stroke. 2003;34(5):1230-4. 
19. Inatomi Y, Yonehara T, Hashimoto Y, et al. Pre-hospital delay in the use of intravenous rt-PA for acute ischemic stroke in Japan. J Neurol Sci. 2008;270: $127 e 32$.

20. Katzan IL, Graber TM, Furlan AJ, et al. Cuyahoga County operation stroke speed of emergency department evaluation and compliance with National Institutes of neurological disorders and stroke time targets. Stroke. 2003;34: 994e8.

21. Hong ES, Kim SH, Kim WY, Ahn R, Hong JS. Factors associated with prehospital delay in acute stroke. Emerg Med J. 2011;28(9):790.

22. Maestroni A, Mandelli $C$, Manganaro D, et al. Factors influencing delay in presentation for acute stroke in an emergency department in Milan, Italy. Emerg Med J. 2008;25:340e5.

23. Song D, Tanaka E, Lee K, Sato S, Koga M, Kim YD, Nagatsuka K, Toyoda K, Heo JH. Factors associated with early hospital arrival in patients with acute ischemic stroke. J stroke. 2015;17(2):159,

24. Tan TY, Chang KC, Liou CW. Factors delaying hospital arrival after acute stroke in southern Taiwan. Chang Gung Med J. 2002;25(7):458-63.

25. Ängerud KH, Brulin C, Näslund U, Eliasson M. Longer pre-hospital delay in first myocardial infarction among patients with diabetes: an analysis of 4266 patients in the northern Sweden MONICA Study. BMC Cardiovasc Disord. 2013;13(1):6.

26. Prohaska TR, Keller ML, Leventhal EA, Leventhal H. Impact of symptoms and aging attribution on emotions and coping. Health Psychol. 1987;6:495-514.

27. Saito E, Gilmour S, Rahman MM, Gautam GS, Shrestha PK, Shibuya K Catastrophic household expenditure on health in Nepal: a cross-sectional survey. Bull World Health Organ. 2014;92(10):760-7.

28. Pokharel R, Silwal PR. Social health insurance in Nepal: a health system departure toward the universal health coverage. Int J Health Plann Mgmt. 2018:33(3):573-80

29. Shrestha GS. A walk after hemiplegia. Intensive Care Med. 2018;44:1957-8,

30. Nepal G, Kharel G, Ahamad ST, Basnet B. Tenecteplase versus Alteplase for the Management of Acute Ischemic Stroke in a low-income country-Nepal: cost, efficacy, and safety. Cureus. 2018;10(2):e2178.

31. Thelengana A, Radhakrishnan DM, Prasad M, Kumar A, Prasad K. Tenecteplase versus alteplase in acute ischemic stroke: systematic review and meta-analysis. Acta Neurol Belg. 2018:4:1-9.

32. Kheiri B, Osman M, Abdalla A, Haykal T, Ahmed S, Hassan M, Bachuwa G, Al Qasmi M, Bhatt DL. Tenecteplase versus alteplase for management of acute ischemic stroke: a pairwise and network meta-analysis of randomized clinical trials. J Thromb Thrombolysis. 2018 Nov 1;46(4):440-50.

33. Akbik F, Hirsch JA, Chandra RV, et al. Telestroke-the promise and the challenge. Part one: growth and current practice. J Neurolnterv Surg. 2017;9: 357-60.

34. Baratloo A, Rahimpour L, Abushouk Al, Safari S, Lee CW, Abdalvand A. Effects of telestroke on thrombolysis times and outcomes: a meta-analysis. Prehosp Emerg Care. 2018;18:1-3.

35. Sharma S, Padma MV, Bhardwaj A, Sharma A, Sawal N, Thakur S. Telestroke in resource-poor developing country model. Neurol India. 2016;64:934-40.

\section{Publisher's Note}

Springer Nature remains neutral with regard to jurisdictional claims in published maps and institutional affiliations.

Ready to submit your research? Choose BMC and benefit from:

- fast, convenient online submission

- thorough peer review by experienced researchers in your field

- rapid publication on acceptance

- support for research data, including large and complex data types

- gold Open Access which fosters wider collaboration and increased citations

- maximum visibility for your research: over $100 \mathrm{M}$ website views per year

At $\mathrm{BMC}$, research is always in progress.

Learn more biomedcentral.com/submissions 